\title{
GESTÃO AMBIENTAL PARA O TURISMO EXCURSIONISTA DO OLHEIRO DE PUREZA-RN: UMA CONTRIBUIÇÃO DA PERCEPÇÃO DE MORADORES E EXCURSIONISTAS
}

\author{
R. L. Lima ${ }^{1}$ e V. P. Silva ${ }^{2}$ \\ ${ }^{1}$ PPGECNM - UFRN e ${ }^{2}$ IFRN - Campus Natal Central \\ rlucas07@hotmail.com; valdenildo.silva@ifrn.edu.br
}

Artigo submetido em maio/2011 e aceito em junho/2011

\section{RESUMO}

O turismo é um fenômeno cuja importância vem crescendo no mundo contemporâneo, devido ao seu caráter transversal e complexo, são múltiplos os desafios para o gerenciamento de suas atividades setoriais. Para levantar informações importantes sobre o ambiente turístico os trabalhos desenvolvidos em percepção ajudam a investigar as relações que uma determinada sociedade tem com o seu ambiente vivencial. Partindo dessas premissas este artigo teve por objetivo responder a seguinte pergunta: qual a percepção do morador e do excursionista sobre o Olheiro de Pureza/RN. E através dessa percepção propor um plano de gestão ambiental para o Olheiro de Pureza/RN. Através das entrevistas, permitiu-se planejar, avaliar, estimular e propor ações mitigadoras dos impactos ambientais; fornecer elementos para as políticas públicas; mas, nada disso será possível sem a imprescindível e efetiva participação da comunidade nas ações públicas, nos processos de decisão, planejamento e no controle social.

PALAVRAS-CHAVE: Turismo, gestão ambiental, percepção.

\section{ENVIRONMENTAL MANAGEMENT FOR TOURISM EXCURSION SCOUTS PUREZA-RN: A CONTRIBUTION FROM THE PERCEPTION OF RESIDENTS AND TOURS}

\begin{abstract}
Tourism is a phenomenon whose importance is growing in the contemporary world due to its transversal and complex; there are multiple challenges for the management of their sectorial activities. To get important information about the tourism environment in the work of perception helps to investigate the relationships that a given society has with its experiential environment. Based on these assumptions this article aimed to answer the following question: what is the perception of residents and the
\end{abstract}

hiker on the Scout Pureza/RN. And through this insight to propose an environmental management plan for the Scout Pureza/RN. Through the interviews allowed to plan, assess, stimulate and propose actions aimed at mitigating the environmental impacts, provide input to public policy, but none of it will be possible without the indispensable and effective community participation in public policies, in decision-making, planning and social control.

KEY-WORDS: Tourism, environmental management, perception. 


\section{GESTÃO AMBIENTAL PARA O TURISMO EXCURSIONISTA DO OLHEIRO DE PUREZA-RN: UMA CONTRIBUIÇÃO DA PERCEPÇÃO DE MORADORES E EXCURSIONISTAS}

\section{INTRODUÇÃO}

O turismo é um fenômeno cuja importância social vem crescendo no curso dos últimos anos. Trata-se de uma das principais atividades que contribui para o desenvolvimento socioeconômico e cultural de um país, além de ser um dos setores que mais apresenta condições favoráveis à conciliação de sua atividade com o meio ambiente (ANDRADE, 2002). Essa atividade vem se constituindo numa das possibilidades de desenvolvimento, pois o Brasil já apresenta uma oferta de 1,1 milhão de apartamentos - unidades hoteleiras (UHs) - e gerando cerca de 500 mil empregos diretos e mais de 1.500.000,00 indiretos. A indústria turística envolve um volume significativo de recursos e patrimônios em torno de US\$ 15 bilhões; receita bruta anual dos seguimentos é de cerca de US\$ 9 bilhões; arrecadação de mais de US\$ 1,8 bilhão em impostos, taxas, contribuições, e grande geração de divisas internacionais. Estima-se que, até o final de 2010, a indústria do turismo do Brasil receberá investimentos da ordem de $R \$ 5,3$ bilhões na construção de novos meios de hospedagem (EMBRATUR, 2008).

Com o turismo as pessoas buscam um tempo de lazer e descanso, já que o confinamento e o constrangimento típicos da vida urbana o tornam uma necessidade, buscam se satisfizer, ao máximo, para se recomporem do stress cotidiano. De acordo com Andrade (2001), a civilização industrial e o ambiente tumultuado, barulhento e desumano que as grandes cidades causam, criam um estado de tal opressão que obriga os indivíduos, mesmo os mais equilibrados, a procurarem durante as férias, finais de semana e feriados, lugares com belezas naturais, pessoas e culturas diferentes, para uma reciclagem e recomposição da energia, mesmo porque o desejo de evasão é humano, natural, freqüente e é produto característico de grandes metrópoles.

Diante da necessidade de se deslocar espontaneamente, por período limitado para fora do local de sua residência habitual, um tipo de turismo que tem crescido é o excursionista, uma vez que o excursionismo é uma tendência cada vez maior dos moradores das grandes cidades pela sua praticidade (FELLINI, 1983). O excursionista permanece por menos de vinte e quatro horas em receptivo ou localidade que não seja o de sua residência fixa, com as mesmas finalidades que caracterizam o turista, mas sem pernoitar no local visitado, pode-se usar o termo excursionista ou visitante de um dia (ANDRADE, 2002).

Esse visitante de um dia busca satisfazer sua necessidade de lazer e descanso em um período curto de tempo, o local visitado deve causar um impacto na motivação pessoal, nas emoções, valores, interesses e outros estados mentais que influenciaram no seu retorno ao local de sua residência (ANDRADE, 2002).

O Município de Pureza, situado a $59 \mathrm{~km}$ da capital Natal, com uma área é de 504,32 $\mathrm{km}^{2}$, é o local onde está localizado Olheiro de Pureza (Figura 1.) situado em pleno centro da cidade, com suas águas cristalinas, abastece cinco cidades circunvizinhas - João Câmara, 
Taipu, Poço Branco, Bento Fernandes, Parazinho, além de ser o local da nascente do Rio Maxaranguape que ocupa uma superfície de $1.010 \mathrm{~km}^{2}$ (IBGE, 2009).

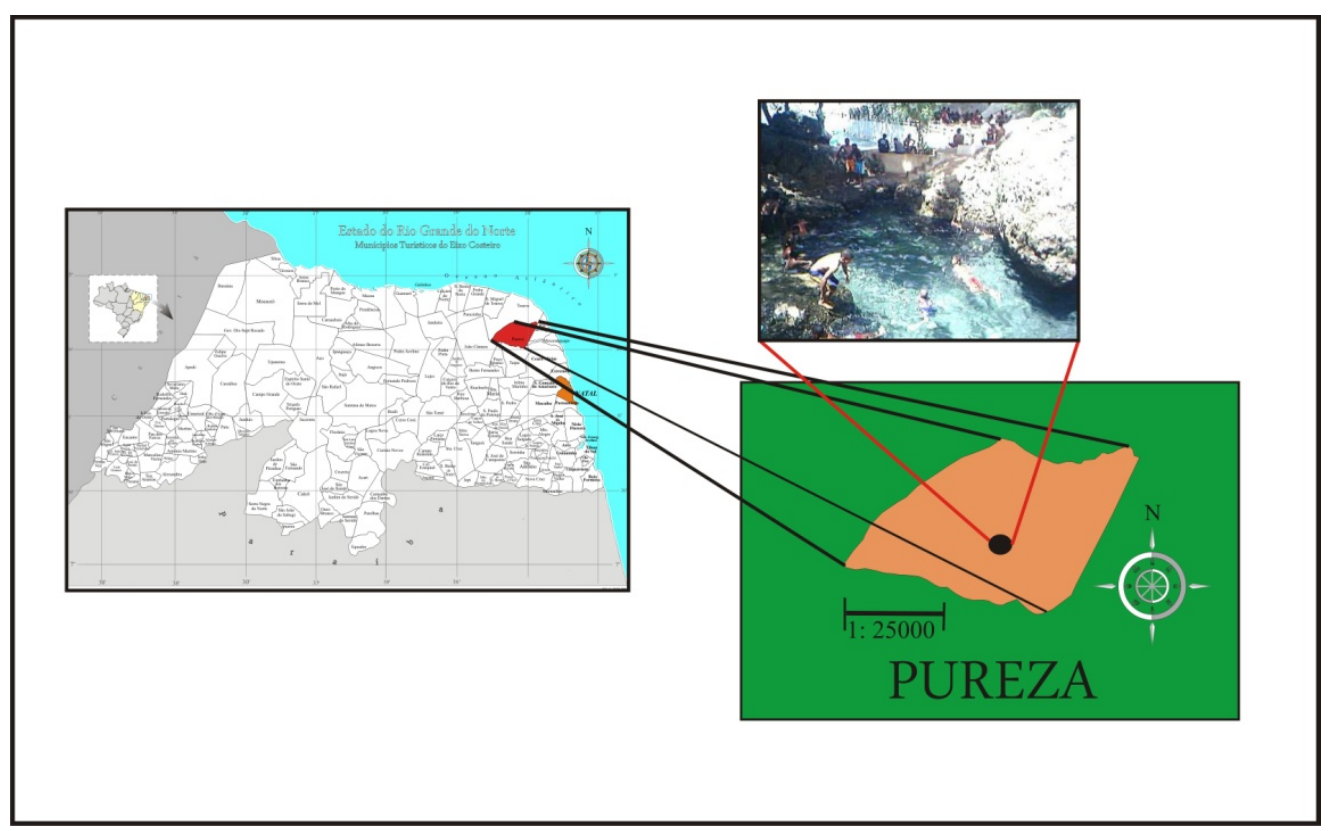

Figura 1 - Mapa mostrando a localização do município de Pureza/RN.

Cartografia: Adriano Eduardo Lívio Alves, 2010.

É através da percepção que o indivíduo tem sobre o ambiente visitado que ele desenvolve suas observações de acordo com seus valores e importância de significados, diferença de culturas, de grupos socioeconômicos, que desempenham funções distintas no plano social (DAY, 1974).

Segundo Davidoff (1983), por meio da percepção desenvolvemos a consciência do ambiente que nos cerca e de nós mesmos, define-se como o processo de organizar e interpretar dados sensoriais recebidos (sensações). Nesse sentido, Day (1972) afirma que a percepção pode ser definida como o contato que o organismo mantém com seu ambiente, seu estado interno, sua própria postura e movimento no espaço.

É por meio da percepção do próprio consumidor, suas observações e necessidades atingidas ou não é possível identificar as deficiências de um determinado segmento ou localidade, e propor melhorias para o melhor funcionamento do ambiente receptivo.

É por meio da percepção dos moradores e excursionistas e da gestão ambiental que este trabalho tem o objetivo de tentar responder estas perguntas: qual a percepção do 
morador e do turista excursionista sobre o Olheiro de Pureza/RN? E através dessa percepção propor um plano de gestão ambiental para o Olheiro de Pureza/RN.

Para a consecução dessa pesquisa foi feito inicialmente uma revisão bibliográfica, levantada por meio da leitura de livros, revistas científicas, teses, dissertações, e em seguida utilizou-se a pesquisa de campo, cuja técnica escolhida foi o estudo de caso de acordo com Gil (2002), porque é a mais flexível e que permite analisar o maior número de ângulos do problema. A coleta dos dados ocorreu por meio de entrevistas semi-estruturadas junto aos visitantes do Olheiro. As entrevistas foram realizadas em um final de semana, dias de maior freqüência de visitantes, com 11 pessoas, 6 moradores e 5visitantes, sendo 2 mulheres e 9 homens, com faixa etária entre 21 e 61 anos, sendo a idade média 32 anos, com abordagem de forma aleatória, mas focando numa analise qualitativa, tendo como embasamento as falas dos entrevistados. Entre os moradores apenas um não é nascido no município, mas mora na cidade há 10 anos, todos os outros moram na cidade a vida toda e possuem residência fixa no município. Entre os visitantes, 3 residem em Natal capital do estado e 2 no município de Parnamirim na região metropolitana de Natal.

Para se chegar a um número limite de entrevista foi utilizado o critério conhecido como de "saturação", que ocorre no suceder da pesquisa, quando as entrevistas/argumentos começarem a se repetir, isto significa, que entrevistar uma maior quantidade de sujeitos pouco acrescentaria no conteúdo da representação (SÁ, 1998).

O tratamento das informações foi feito a partir do discurso dos moradores e excursionistas sobre sua opinião acerca do Olheiro de Pureza/RN, segundo Chizzotti (1998), cujo objetivo é compreender criticamente o sentido das comunicações, seu conteúdo manifestado ou latente, as significações explicitas ou ocultas.

Além dessa parte introdutória o presente artigo está estruturado em mais três seções. Na primeira, apresentamos uma fundamentação de referência teórica. Em seguida uma breve caracterização do município de Pureza e sua história recente. Por fim, apresentamos as nossas considerações finais e as referencias do estudo.

\section{FUNDAMENTAÇÃO TEÓRICA}

O turismo é característico de uma sociedade de consumo como um todo estruturado, é mais um produto ou uma combinação de bens e serviços, cuja funcionalidade depende de uma série de conhecimentos operacionais e de paciente dedicação para atendimento cabal dos requisitos da oferta e das exigências da demanda (ANDRADE, 2002).

O conceito de turismo é uma matéria bastante polêmica segundo vários autores que tratam desse assunto. O turismo está relacionado a viagens, mas nem sempre todas as viagens são consideradas como turismo (IGNARRA, 2002). Conforme Ignarra (2002), a Organização Mundial do Turismo (OMT) define turismo como sendo "o deslocamento para fora do local de residência por período superior a 24 horas e inferior a 60 dias motivado por 
razões não-econômica". Essa definição serve apenas para padronizar o conceito de turismo em todos os países que são membros da organização.

Para muitos especialistas, turismo são as viagens para regiões que se distanciam mais de $80 \mathrm{~km}$ dos locais de residência (LAGE; MILONE, 2001). Outros especialistas, ao conceituar turismo, definem como sendo os viajantes que permaneçam mais de 24 horas nos locais visitados e que não exerçam atividade lucrativa nem remunerada.

Dessa forma, Ignarra (2002), define o turismo como o deslocamento de pessoas de seu local de residência habitual por períodos determinados por motivo de recreação, descanso, cultura ou saúde e não motivados por razões de exercício profissional constante. Segundo esse autor, segue um exemplo:

Uma pessoa que reside em um município e se desloca para outro diariamente para exercer sua profissão não estará fazendo turismo. Mas o profissional que esporadicamente viaja para participar de um congresso ou para fechar um negocio em outra localidade que não à de sua residência estará fazendo turismo. (IGNARRA, 2002, p. 25)

Para a realização de uma atividade turística é necessário que ocorra o deslocamento de pessoas a localidades diversas da cidade onde o visitante possui residência fixa. Assim os viajantes são tidos como consumidores de serviços turísticos como hospedagem, produtos alimentícios, transporte, produtos regionais típicos, qualquer que sejam suas motivações. Porém a OMT classifica esses consumidores em turistas, excursionistas e visitantes (ANDRADE, 2002).

\section{TURISTA E EXCURSIONISTA: PARTICULARIDADES}

Para ser considerado um turista, além de preencher as características exigidas pelo fenômeno, como se deslocar do seu local de residência por motivo de lazer e entretenimento, o visitante deve permanecer no local por um período superior a 24 horas.

Desta forma o turista é aquele que viaja com o objetivo de não se preocupar com o retorno imediato ao seu local habitual.

Segundo Ignarra (2002), a Organização das Nações Unidas (ONU) adotou em 1954 o conceito de turista como: "Toda pessoa, sem distinção de raça, sexo, língua e religião, que ingresse no território de uma localidade diversa daquela em que tem residência habitual e nele permaneça pelo prazo mínimo de 24 horas e máximo de seis meses, no transcorrer de um período de 12 meses, com finalidade de turismo, recreio, esporte, saúde, motivos familiares, estudos, peregrinações religiosas ou negócios, mas sem propósito de imigração".

Para Andrade (1998), o turista é a pessoa que, livre e espontaneamente, por período limitado, viaja para fora do local de sua residência habitual, a fim de exercer ações que, por sua natureza e pelo conjunto das relações delas decorrentes, classificam-se em algum dos tipos, das modalidades e das formas de turismo. 
O excursionista, de acordo Andrade (2002) é classificado pela OMT como visitante que permanece por menos de vinte e quatro horas em receptivo ou localidade que não seja o de sua residência fixa, com as mesmas finalidades que caracterizam o turista, mas sem pernoitar no local visitado, pode-se usar o termo excursionista ou visitante de um dia. A definição de turista adotada pela Assembleia Geral da União Internacional dos Organismos Oficiais de Turismo (UIOOT, 1969), apresentada por Andrade (2002), distingue o excursionista como uma categoria que se caracteriza pelo fato único de não pernoitar no local visitado.

O termo visitante é considerado como equivalente a excursionista, embora especifique gênero e não espécie. Ignarra (2002), diz que nos casos de turismo marítimo ou fluvial de habitantes do próprio pais ou estrangeiros, o termo visitante designa tanto o turista como o excursionista, pois é um termo técnico internacional discriminatório de passageiros que permanecem embarcados. Definidos os conceitos de turismo, turista e excursionista, o visitante do Olheiro de Pureza segundo os referenciais teóricos acima esta enquadrado na categoria de excursionista, pois passam um período inferior a 24 horas no local de visita.

\section{PERCEPÇÃO: UMA BREVE DISCUSSÃO}

É possível identificar as deficiências de um determinado segmento seja publico ou privado, se está ou não atendendo as necessidades do publico, através da percepção do próprio consumidor turista ou excursionista, por meio de suas observações e necessidades atingidas ou não, e propor melhorias para o sistema turístico empregado em uma localidade.

Para, Tuan (2002), a percepção é o processo de organizar e interpretar sensações, necessárias para o desenvolvimento da consciência sobre o ambiente que nos cerca e de nós mesmos. A motivação pessoal, as emoções, os valores, os interesses e outros estados mentais influenciam o que as pessoa percebem, diferenciando o sentido de percepção entre pessoas.

Segundo, Day (1972), a percepção, como área da psicologia, pode ser adequadamente considerada como o conjunto de processos pelos quais o individuo mantém contato com o ambiente. Para sobreviver num ambiente de objetos e eventos físicos o individuo precisa ajustar-se continuamente à variedade de energias, em constante mudança, que o cercam. A totalidade dos processos envolvidos na manutenção de contato com este mundo de energia é a percepção.

Por sua vez Davidoff (1983), define a percepção como sendo o processo de organizar e interpretar dados sensoriais recebidos (sensações) para desenvolvermos a consciência do ambiente que nos cerca e de nós mesmos. A percepção implica interpretação. Nossos sentidos podem ser considerados como nossas janelas para o mundo.

Dessa forma, o estudo da percepção neste trabalho se torna importante para que se possa compreender melhor, de acordo com Fontenele, 2004, as inter-relações do homem com o ambiente, suas expectativas, satisfações e insatisfações, julgamentos e condutas. É através da percepção que o indivíduo tráz sobre o ambiente em que ele mantém contato e seu estado interno, de acordo com seus valores e importância de significados, diferença de 
culturas, de grupos socioeconômicos que desempenham funções distintas, no plano social. Pois, a valorização do ambiente pelo visitante está na existência de percepções dos valores que o individuo da para as condições do local em que ele ira permanecer durante sua estadia.

\section{GESTÃO AMBIENTAL}

O conceito de gestão ambiental, segundo Valle (2000), consiste em um conjunto de medidas e procedimentos bem definidos e adequadamente aplicados que visam a reduzir e controlar os impactos introduzidos por um empreendimento sobre o meio ambiente. Barbieri (2004) define gestão ambiental como sendo as diretrizes e as atividades administrativas e operacionais, tais como planejamento, direção e controle, com o objetivo de obter efeitos positivos sobre o meio ambiente, reduzindo ou eliminando os danos causados pelas ações humanas ou mesmo evitando seu surgimento.

Um ponto importante na gestão ambiental é a definição de uma política ambiental para as empresas que desejam demonstrar sua responsabilidade ambiental ou ecológica. Para Barbieri (2004), a política ambiental é um documento no qual entidade pública e privada informa as intenções e princípios de seu desempenho global para, então, estruturar-se para ação e definir metas e objetivos ambientais. Um fator crítico do sucesso para incorporação da variável ambiental pelas empresas é a sensibilização ambiental dos dirigentes seja ele um empresário de grande ou pequeno porte, uma prefeitura ou governo em qualquer uma das suas instâncias. Valle (2000) considera esta uma medida capaz de provocar alterações em suas prioridades estratégicas e algumas mudanças de abordagem que vão modificar as atitudes e o comportamento de todos os que usufruem do mesmo espaço social.

A busca do equilíbrio necessário para o desenvolvimento de atividades que beneficie a conservação ambiental, as comunidades receptoras e os turistas envolve, um planejamento de diversos setores como públicos e privados, além da comunidade. Para propor melhorias para os possíveis problemas apontados por moradores e excursionistas na prática do turismo, a Gestão Ambiental disponibiliza ferramentas que objetivam proporcionar condições ambientais e sociais adequadas para prática do turismo.

\section{CARACTERIZAÇÃO DA AREA DE ESTUDO: O MUNICÍPIO DE PUREZA/RN}

O Município de Pureza teve inicio no ano de 1806, nas terras de nome Pau Ferro de propriedade de Leopoldo Rodrigues Braga. Era um pequeno povoado ladeado por árvores chamadas pau-ferro, que faziam sombra sobre as pedra de onde brotava o manancial de água que irriga o leito do rio Maxaranguape. Por volta de 1879 o Dr. José Inácio Fernandes Barros, um freqüentador da localidade e defensor das qualidades medicinais das águas límpidas das nascentes, o povoado passou a se chamar Pureza e no dia 25 de maio de 1891, a povoação de Pureza foi elevada à categoria de distrito. Seu ritmo gradativo de prosperidade continuava. Surgiu à feira semanal, veio à primeira escola e foi construída a capela de Nossa Senhora da Pureza. 
No ano de 1930, o distrito de Pureza era considerado o mais próspero do município de Touros e em outubro de 1938 foi elevado à vila, permanecendo assim até dezembro de 1943, quando a localidade passou a se chamar vila de Maxaranguape, nome que permaneceu até sua emancipação em 5 de abril de 1963 . Através da Lei $n^{\circ} 2.882$, desmembrou-se de Touros tornando-se município do Rio Grande do Norte e retornando ao histórico e definitivo nome de Pureza (IBGE, 2004). O município possui uma população de 8.415 habitantes no ano de 2009, segundo dados do IBGE, censo 2009.

\section{O Olheiro de Pureza}

Em pleno centro da cidade, o Olheiro de Pureza (Figura 2) também conhecido como Fonte de Pureza, com suas águas cristalinas abastece cinco cidades circunvizinhas Parazinho, Taipu, João Câmara, Poço Branco, Bento Fernandes, além de ser o local da nascente do Rio Maxaranguape que ocupa uma superfície de $1.010 \mathrm{~km}^{2}$, correspondendo em torno de $1,9 \%$ da área do estado. O Rio Maxaranguape é considerado rio de baixa extensão, ele banha somente os municípios de Ceará-Mirim e Maxaranguape, onde deságua no oceano Atlântico formando um estuário, nas suas várzeas encontra-se solo aluvial, onde são cultivadas a cana-de-açúcar e a banana (CPRM, 2005).

Segundo Guerra (1978), olheiro é a designação dada aos locais onde se verifica o aparecimento de uma fonte ou mina de água. As áreas onde aparecem olhos-d'água são, geralmente em terrenos rochosos, planos e brejosos.

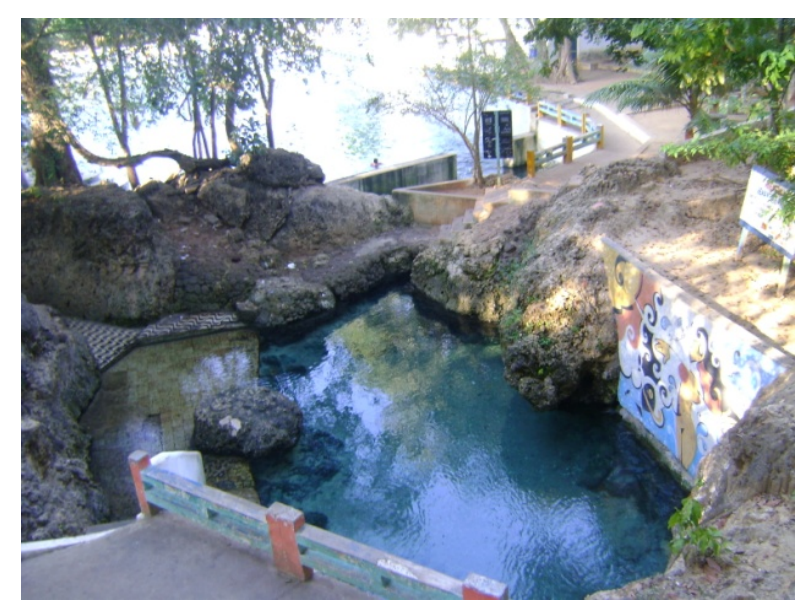

Figura 2 - Pureza/RN, fonte natural do "Olheiro" nascente do Rio Maxaranguape.

Fonte: Rodrigo, 2010.

Por estar localizado no centro da cidade e ser um resquício de área natural, o Olheiro acaba atuando como agente impulsionador da economia local, através da geração de emprego e renda, por outro lado, se o local não estiver sendo administrado de forma 
adequada, de acordo com Melo (2005), pode gerar alterações nos processos ecológicos dos ecossistemas, descaracterizando-os e contribuindo para o empobrecimento biológico, ecológico, paisagístico e cênico. Com o aumento do uso destas áreas naturais pelo excursionismo na busca por locais agradáveis para fins de lazer, descanso e recreação, constitui uma necessidade à busca de técnicas adequadas para avaliar, aplicar medidas mitigadoras e difundir informações adequadas sobre a relação entre ecologia e lazer (MIDAGLIA, 1999).

\section{GESTÃO AMBIENTAL PARA O TURISMO EXCURSIONISTA DO OLHEIRO DE PUREZA-RN: UMA CONTRIBUIÇÃO DA PERCEPÇÃO DE MORADORES E EXCURSIONISTAS}

A análise da percepção dos moradores e dos excursionistas do Olheiro de Pureza ocorreu por meio da identificação de seus discursos sobre o que eles julgavam sobre o Olheiro. As entrevistas foram realizadas no mês de agosto em dois momentos: o primeiro, com os moradores da cidade em um sábado, dia de feira e de movimento na cidade, já as entrevistas com os visitantes foram realizadas no domingo no próprio Olheiro dia de maior movimento excursionista no local.

Os moradores foram perguntados sobre a opinião que eles têm sobre o olheiro de Pureza, as primeiras palavras foram observadas nos discursos a seguir:

"O olheiro precisa mais de zelo, de saneamento básico, ainda tem muito sistozama..."

"... o olheiro é uma fonte muito produtiva, é muito importante para o nosso município..."

"O olheiro do meu ponto de vista, para o turismo ele é muito bom."

O olheiro ainda é tido como principal atrativo e impulsionador econômico do município, servindo também como grande divulgador da cidade. Percebe-se que os moradores possuem um cuidado, um carinho com o Olheiro da sua cidade, principalmente por terem vividos sua infância e adolescência no local. Porém, não estão aprovando a situação atual em que o local se encontra. Esse desconforto com o momento atual apontado pelos entrevistados transcreve-se nos discursos abaixo:

"Hoje eu vejo que ninguém olha para o Olheiro, principalmente as autoridades, tá abandonado."

"Eu tomava banho aqui no tempo que não tinha nenhuma construção, era bom."

"... a condição dele agora não está boa, tá muito abandonado, principalmente pelas autoridades." 

muito."

"... ele ta num jeito que vai ser extinto se continuar do jeito que tá e não vai demorar

Por meio desses depoimentos dados pelos moradores dá para perceber que há uma insatisfação destes com o encaminhamento realizado pela Prefeitura Municipal. As autoridades públicas não estão investindo de forma adequada na preservação da fonte inclusive na segurança da estrutura do local (Figura 3), devido ao afundamento de parte do pavimento em torno do Olheiro, fato relatado pelos moradores no discurso a seguir:

"Agora tá interditado, eu acho que o povo só toma banho do outro lado maior."

“... a prefeitura deve achar um órgão de fora para fazer o serviço no Olheiro."

"Essa semana a prefeita tava dizendo que parte da fonte tava interditado e que foi a bomba de água da CAERN que causou a queda da barreira."

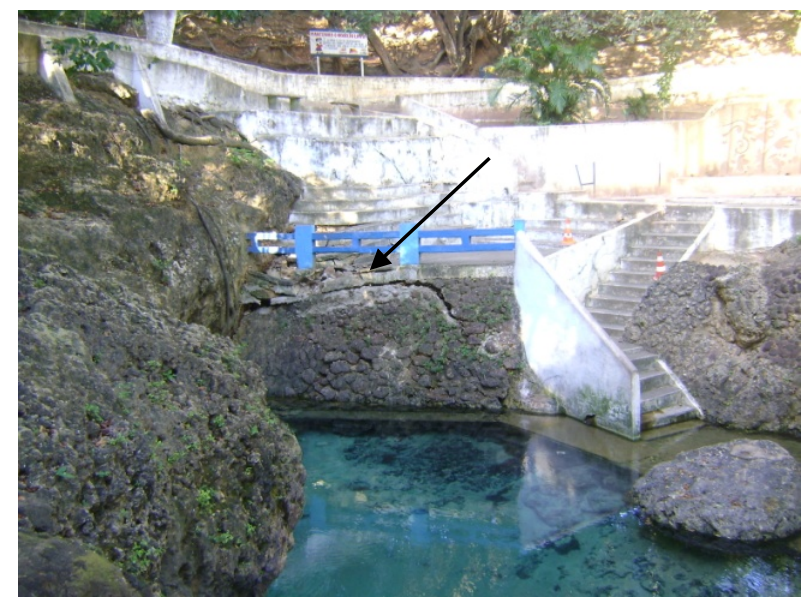

Figura 3 - Olheiro de Pureza/RN, escorregamento da barreira lateral a cabeceira. Fonte: Rodrigo, 2010.

Por meio desses relatos percebe-se o quanto os moradores estão interessados nas informações sobre a fonte de sua cidade e atentos as condições atuais do local. Pois, os problemas apontados pelos moradores refletem também no fluxo de visitantes e na renda da população que vive do excursionismo no Olheiro.

O fluxo dos visitantes é um ponto colocado em todas as falas dos moradores, tanto de forma positiva como negativa, a primeira, pela satisfação de receber visitantes, a renda deixada no município, a movimentação da cidade, e a segunda, causada pela sujeira dos banhistas, o vandalismo tanto com a natureza quanto com os agentes artificiais em volta. Tais pontos observados seguem no discurso a seguir:

"O turismo é muito bom, o turista vem deixa renda e emprego aqui." 

papel,..."

"O turismo é bom, mas por outro lado agente ver o rio cheio de lixo, copo descartável,

"O turista vem sobe lá pra cima com um monte de coisa se aloja para fazer fogo, ai fica arrancando parte da casca das árvores e parte da raiz."

"Tem domingo que chega a ter 30 ônibus, fica muito lotado."

Mesmo com apontamentos positivos e negativos dados pelos moradores sobre os excursionistas do Olheiro, eles admitem que o local não oferece uma infra-estrutura adequada para recepção e acomodação do publico excursionista. A partir do momento em que não há uma oferta, por exemplo, de banheiros, vestiários, duchas, pontos de alimentação com preços acessíveis, lixeiras em quantidades suficientes, programas de conscientização e fiscalização, e tudo isso somado a grande quantidade de excursionistas disputando o mesmo lugar, acaba por incentivar as atitudes descritas. Talvez partes destes comportamentos reflitam o descaso que os visitantes sofrem por parte do poder publico municipal.

Cabe ao poder publico e a comunidade traçar metas para uma organização dos sistema administrativo do Olheiro, visando melhorar a infra-estrutura para acomodação e recepção dos visitantes, fortalecendo o seu vinculo com o local e propiciando uma maior oportunidade para geração de renda e divisas para o município.

Um fator proposto nas entrevistas pelos moradores é a privatização do banho ou pelo menos uma cobrança para permanecer no local do banho, conforme trechos da entrevista a seguir:

"Todo canto que a pessoa vai paga alguma coisa, era para cobrar pelo menos qualquer coisa para manutenção do Olheiro."

"Era para pelo menos limitar o pessoal na fonte pagando, tem muita gente ao mesmo tempo tomando banho."

Por meio dessas respostas percebe-se que mesmo trazendo vantagens para cidade o turismo no local não esta sendo feito de forma organizada e que os órgãos competentes não estão dando conta da manutenção da fonte.

Do ponto de vista dos visitantes outros pontos foram relatados nas entrevistas, local em que foi feito a mesma pergunta, qual a opinião que eles têm sobre o olheiro de Pureza, as primeiras palavras foram observadas nos discursos a seguir:

"Vejo ele como uma atração turística para a cidade."

"O Olheiro é uma fonte de riqueza para cidade, assim como a questão da água."

"É uma beleza natural show de bola que gera renda para cidade." 
Por meio dessas entrevistas percebe-se que o turista ao conhecer o Olheiro de Pureza ele se admira com o local, se permitindo usufruir desse momento de vislumbre, alcançando nesse breve instante seu desejo de lazer e descanso.

Mas a primeira impressão logo é deixada de lado com o passar das horas quando cada visitante busca se acomodar em determinado local para passar o dia, eles percebem que o local não esta recebendo os devidos cuidados de manutenção por parte da prefeitura, como relatado nos seguintes discursos:

"Hoje parece esta meio abandonado."

"No meu ponto de vista ta faltando organização, tem muita gente, meio desorganizado."

"Não vejo a prefeitura investindo numa estrutura melhor..."

"... a organização nos dias de banho porque fica aquele tumulto lá dentro."

Mesmo passando um período curto de tempo no local visitado o excursionista consegue valorizar a natureza e ao mesmo tempo perceber os problemas do local no que diz respeito à falta de manutenção e infraestrutura. Segundo Andrade (2001) o visitante observa todas as condições sociais e ambientais locais durante todo seu período em receptivo.

Da mesma forma, os moradores, os visitantes também, apontaram a responsabilidade da falta de organização e estrutura local para entidades publicas, apesar de que um entrevistado ter apontado os moradores da cidade como os responsáveis pela falta de organização, como seguem os depoimentos a seguir:

"Eu acho que a administração da prefeitura é ruim e segundo os moradores não zelam pelo principal ponto de lazer da cidade."

Não sendo confirmada essa responsabilidade aos moradores nas demais entrevistas:

"É bonito aqui, só precisa de uma organização maior da prefeitura"

"Falta organização, acho que a prefeitura não esta trabalhando muito aqui não."

"Falta administração chegar junto e organizar o povo."

"Não vejo atitude com a qualidade do banho, a prefeitura devia limitar as pessoas aqui."

Após as análises das entrevistas com os moradores e excursionistas a respeito de observações sobre o Olheiro de Pureza, percebeu-se que esses vêem o olheiro como um bem muito precioso e que necessita ser preservado e melhor gerido pelos órgãos públicos competentes. Sendo que parte desses problemas também se deve a população em geral, pois 
para minimizar os problemas relatados é necessária uma participação direta e consciente de toda sociedade.

\section{PROPOSTA PARA UM PLANO DE GESTÃO AMBIENTAL}

Para um plano de gestão ambiental ter sucesso é importante destacar que, no contexto de uma cidade com vocação turística como Pureza, é essencial que as mudanças ultrapassem os limites do município, transformações de caráter estrutural não ocorrem sem a integração com investimentos federais e estaduais e até mesmo privados. Mesmo fora da responsabilidade da esfera municipal, ações de outras instâncias estão presentes em um planejamento da gestão pública, porque produzem resultados que provocam grandes impactos sobre a cidade. É o caso, por exemplo, de intervenções em áreas de mananciais (Andrade et al., 2002).

\section{Responsabilidade.}

Para isso o Estado por meio do Instituto de Desenvolvimento e Meio Ambiente do RN IDEMA possui a Gestão Ambiental Compartilhada, esse processo previsto pela Política Nacional de Meio Ambiente pelo qual, através de uma repartição adequada de responsabilidades e recursos, se estabelecem cooperação e integração entre os entes da federação, de forma a se assegurar a qualidade ambiental necessária à manutenção e melhoria da qualidade de vida e a um uso sustentável dos recursos naturais. Essa atribuição seria compartilhada entre o Estado, por meio IDEMA, e os Municípios, desde que atendidos alguns critérios técnicos e institucionais. (GOVERNO DO ESTADO DO RN, 2009).

\section{Sustentabilidade}

A sustentabilidade é um tema obrigatório na agenda de todas as cidades, sobretudo, numa cidade como Pureza que deve combinar desenvolvimento, atendimento às demandas sociais e turísticas juntamente com a preservação do meio ambiente. O desafio é articular práticas voltadas para minimizar os impactos ambientais produzidos pelas atividades urbanas e turísticas e políticas de preservação e controle ambiental, com a busca por melhor qualidade de vida dos cidadãos.

As ações voltadas para o crescimento sustentado envolvem melhorias urbanísticas, maior mobilidade, ampliação e preservação da cobertura vegetal, controle das emissões sonoras, manejo dos resíduos sólidos e preservação dos recursos hídricos.

Essas ações devem garantir a preservação da mata nativa entorno do Olheiro e principalmente da cabeceira (Figura 4) e garantir que o crescimento urbano ocorra de maneira sustentável. 


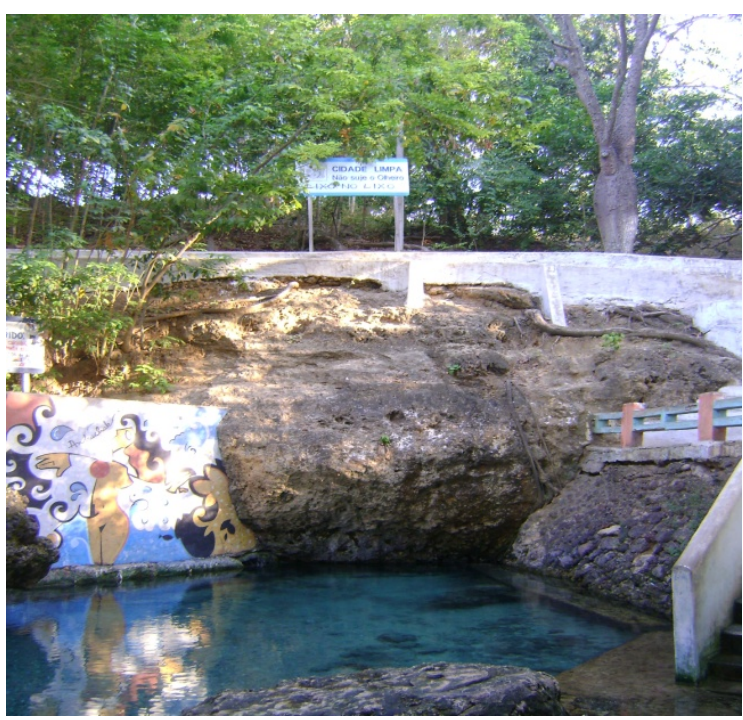

Figura 4 - Região conhecida como a Cabeceira do Olheiro.

\section{Eficiência das ações}

Garantir agilidade, transparência, responsabilidade com dinheiro público e justiça fiscal às políticas municipais. Pureza é uma cidade em constante transformação política, com grande potencial a prestação de serviços. Essa característica exige do Poder Pública atualização permanente de instrumentos de gestão que se traduzam no melhor atendimento ao cidadão, ao visitante e empresário. O desafio é romper os paradigmas burocráticos e implementar formas inovadoras de gestão, orientadas pelos princípios da eficiência e da responsabilidade no gasto do dinheiro público. Saber gastar é o ponto de partida para uma gestão moderna e eficaz.

\section{Potencialidade turística}

Aproveitar as potencialidades turísticas da cidade para promover o desenvolvimento econômico e social. Porém, traz muitas outras responsabilidades, como a formação de profissionais, pois sendo turismo uma atividade geradora de riquezas, tem a necessidade de mão de obra em quantidade e qualidade (LAGE, MILONE, 2000). Portanto, o desafio que se apresenta é colocar esse potencial turístico, os talentos e o conhecimento gerado ao longo dos anos, a experiência de sucesso no cenário regional, para incentivar alem das atividades turísticas as culturais e esportivas, a preservação do patrimônio e a recuperação de espaços públicos e criação de uma nova infraestrutura urbana, acessíveis a todos. O Impacto local dessas ações é imediato, uma vez executada a ação, seus efeitos afetaram não penas o município de Pureza, mas as suas imediações e toda região do mato grande, ultrapassando os limites municipais. 


\section{CONSIDERAÇÕES FINAIS}

O desenvolvimento deste trabalho possibilitou evidenciar por meio da fala dos moradores e excursionistas as mudanças socioambientais necessárias para melhoria das condições locais. As entidades públicas necessitam criar um plano de gestão turística com participação da população, e, também, ouvindo os visitantes do Olheiro.

O conhecimento da percepção pela população local e pelos visitantes sobre o meio ambiente e o local em que eles compartilham, permite ao gestor planejar e elaborar projetos em Gestão Ambiental; avaliar, estimular e propor ações mitigadoras dos impactos ambientais; fornecer elementos para as políticas públicas; mas, nada disso será possível sem a imprescindível e efetiva participação da comunidade nas políticas públicas, nos processos de decisão, planejamento e no controle social. Além disso, pode-se dizer que os problemas relatados pelos purezense, como falta de organização, sujeira, vandalismo, lotação do espaço, se deve ao descaso dos moradores e a falta de efetivo policial no local. Os habitantes e as entidades públicas da cidade, em sua maioria, agem individualmente, de acordo com os próprios interesses, desconsiderando o meio ambiente e a coletividade do local.

O caminho para a solução dos problemas socioambientais do Olheiro de Pureza fica explicitado: compromisso populacional e político em relação aos assuntos socioambientais. Para tanto, faz-se necessário uma mudança das concepções e atitudes individuais dos habitantes, políticos locais e principalmente dos excursionistas, pelo menos em relação ao Olheiro, o que pode ser obtido a partir do desenvolvimento de uma atitude ética e de práticas de educação e gestão ambiental que estejam ao alcance de todos. Acontecendo isso, espera-se que a sociedade purezense encontre o seu próprio caminho para a sustentabilidade de sua maior fonte de riqueza.

\section{REFERÊNCIAS}

1. ANDRADE, R. O. B.; CARVALHO, A. B.; TACHIZAWA, T. Gestão ambiental: enfoque estratégico aplicado ao desenvolvimento sustentável. São Paulo: Makron Books, 2000. $232 \mathrm{p}$.

2. ANDRADE, J. V. Turismo: Fundamentos e dimensões. São Paulo: Ed. Ática. 5 ed. 1998. $214 \mathrm{p}$.

3. Gestão em lazer e turismo. Belo Horizonte: Autêntica, 2001. 176 p.

4. BAY, A. M. C.; SILVA, V. P. da. Percepção ambiental de moradores do bairro de liberdade de Parnamirim sobre a implantação do esgotamento sanitário. Natal, 2009.

5. BARBIERI, J. C. Gestão ambiental empresarial: conceitos, modelos e instrumentos. São Paulo: 2004. 
6. BENI, M. C.. Análise estrutural do turismo. São Paulo: SENAC, 2000.

7. Política e planejamento de turismo no Brasil. São Paulo: Ed. Aleph, 2006.

8. BEZERRA, A. K. P. P. Gestão ambiental no turismo: um estudo sobre a percepção do turista com relação à importância de práticas ambientais em hotéis. 98 f., il. Dissertação (Mestrado em Engenharia de Produção) - Universidade Federal Rio Grande do Norte, Natal, 2004.

9. DAY, R. H. Percepção humana. Rio de Janeiro: Livros Técnicos e Científicos, 1972. 189 p.

10. DAY, R. H. Psicologia da percepção. 2 ed. Rio de Janeiro: J Olympio, 1974. 120 p., il. (Psicologia contemporânea).

11. FELLINI, L. Turismo: uma atividade municipal. In: Políticas públicas de turismo: a hospitalidade pública ao excursionista em Bertioga. Profa M. Silvia Rubino (UAM). Porto Alegre: Est. 1983.

12. FONTENELE JÚNIOR, A. M. Percepção socioambiental: a visão de turistas e residentes de Guaramiranga-CE. 2004. 117 f. Dissertação (Mestre) - Universidade Federal do Ceará, Fortaleza, 2004. Disponível em: <www.prodema.ufc.br/dissertacoes/102.pdf >. Acesso em: 17 jul. 2010.

13. GIL, A. C. Métodos e técnicas de pesquisa social. São Paulo: Atlas, 1999. 5 ed. 206 p.

14. . Antonio Carlos. Como elaborar projetos de pesquisas. 4 ed. São Paulo: Atlas, 2002. 4 ed. 175 p.

15. Governo do estado do Rio Grande do Norte. Plano de Gestão Ambiental compartilhada do estado do Rio Grande do Norte (Licenciamento, Fiscalização e Monitoramento Ambiental), $2009 . \quad$ Disponível em: <http://www.portal.rn.gov.br/contentproducao/aplicacao/idema/licenciamento_ambi ental/arquarqu/projeto\%20de\%20gest\%C3\%A3o\%20compartilhada\%20do\%20rn\%20j ulho2009.pdf>. Acesso em 26 ago. 2010.

16. Instituto Brasileiro de Turismo - EMBRATUR. Ministério do Turismo: Dados e Fatos. Disponível em: <http://www.turismo.gov.br/dadosefatos>. Acesso em: 30 ago. 2010.

17. Instituto Brasileiro de Geografia e Estatística - IBGE, Banco de dados cidades 2009. Disponível em: <http://www.ibge.gov.br/cidadesat/>. Acesso em: 06 jul. 2010. 
18. Instituto Brasileiro de Geografia e Estatística - IBGE, Resultados da Amostra do Censo Demográfico 2000 - Malha municipal digital do Brasil: situação em 2001. Rio de Janeiro: IBGE, 2004.

19. LAGE, B. H. G.; MILONE, P. C. Economia do turismo. Campinas: Papirus, 1991. 122p.

20. . Turismo: teoria e pratica. São Paulo: Atlas, 2000. 1 ed. 376p

21. LEMOS, L. Turismo: que negócio é esse? Uma análise da economia do Turismo. São Paulo: Papirus, 2001.

22. MACHADO, R. C. A.; GUSMÃO, L. C.; SOARES, C. L. R. S. Percepção sócio-ambiental dos turistas e trabalhadores da praia de Porto de Galinhas (Pernambuco-Brasil) acerca do ecossistema recifal. Gestão Costeira Integrada, Pernambuco, n. 9, p.71-78, 2009.

23. MARIN, A. A. Pesquisa em educação ambiental e percepção ambiental - UFPR Departamento de Teoria e Prática de Ensino-Pesquisa em Educação Ambiental, vol. 3, n. 1 - pp. 203-222, 2008.

24. MELO, R.S, CRISPIM, M.C. \& LIMA, E.R.V. (2005) - 0 turismo em ambientes recifais: em busca da transição para a sustentabilidade. Caderno Virtual de Turismo, 5(4):3442.

em: http://www.ivt.coppe.ufrj.br/caderno/ojs/viewarticle.php?id=105)

25. MIDAGLIA, C.L.V. Turismo e meio ambiente no litoral Paulista: dinâmica da balneabilidade nas praias. In: LEMOS, Amélia Inês G. (org). Turismo - Impactos SócioAmbientais. 20 ed. São Paulo: Hucitec, 1999, p.32-56.

26. OMT - Organização Mundial do Turismo. Turismo Internacional: uma perspectiva global. 2a. ed. Porto Alegre: Bookmann, 2003.

27. ORLANDI, E. P. Análise de discurso: princípios e procedimentos. 8eed. Campinas: Pontes, 2009. 105 p.

28. PINHEIRO, O. de G.. Entrevista: uma prática discursiva. In: SPINK, Mary Jane (org.). Práticas discursivas e produção de sentidos no cotidiano: aproximações teóricas e metodológicas. 3. ed. São Paulo: Cortez, 2004.

29. SÁ, C. P. A Construção do objetivo de pesquisa em representações sociais. In:

A construção do objetivo de pesquisa em representações sociais. Rio de Janeiro: UERJ, 1998. Cap. 5, p. 79-95. 
30. TRIGO, L. G. G. Turismo básico. São Paulo: SENAC, 2002.

31. TUAN, Yi-Fu. Topofilia : um estudo da percepção, atitudes e valores do meio ambiente. São Paulo: Difel, 1980. 288p.

32. VALLE, C. E. Como se preparar para as normas ISO 14000: qualidade ambiental: o desafio de ser competitivo protegendo o meio ambiente. São Paulo: Pioneira, 2000. 